\title{
High Plasma Docosahexaenoic Acid Associated to Better Prognoses of Patients with Acute Decompensated Heart Failure with Preserved Ejection Fraction
}

\author{
Naoaki Matsuo ${ }^{1}$, Toru Miyoshi ${ }^{1, *}{ }^{(}$, Atsushi Takaishi ${ }^{2}$, Takao Kishinoue ${ }^{2}$, Kentaro Yasuhara ${ }^{2}$, \\ Masafumi Tanimoto ${ }^{2}$, Yukari Nakano ${ }^{3}$, Nobuhiko Onishi ${ }^{2}$, Masayuki Ueeda ${ }^{4}$ and Hiroshi Ito ${ }^{1}$ \\ 1 Department of Cardiovascular Medicine, Okayama University Graduate School of Medicine, \\ Dentistry and Pharmaceutical Sciences, Okayama 700-8558, Japan; naoaki.matsuo.1985@gmail.com (N.M.); \\ itomd@md.okayama-u.ac.jp (H.I.) \\ 2 Department of Cardiovascular Medicine, Mitoyo General Hospital, Kagawa 769-1601, Japan; \\ takaishi1013@ybb.ne.jp (A.T.); takao.nakayama.0922@gmail.com (T.K.); ilovesukuramu@yahoo.co.jp (K.Y.); \\ kpggp925@gmail.com (M.T.); nobuohnishi@mitoyo-hosp.jp (N.O.) \\ 3 Nakano Cardiovascular Clinic, Kagawa 762-0012, Japan; nakanocc.20200129@gmail.com \\ 4 Ueeda Cardiovascular Clinic, Kagawa 769-1504, Japan; ueedacvc@gmail.com \\ * Correspondence: miyoshit@cc.okayama-u.ac.jp; Tel.: +81-86-235-7351
}

Citation: Matsuo, N.; Miyoshi, T.; Takaishi, A.; Kishinoue, T.; Yasuhara, K.; Tanimoto, M.; Nakano, Y.; Onishi, N.; Ueeda, M.; Ito, H. High Plasma Docosahexaenoic Acid Associated to Better Prognoses of Patients with Acute Decompensated Heart Failure with Preserved Ejection Fraction. Nutrients 2021, 13, 371. https://doi.org/ $10.3390 /$ nu13020371

\section{Academic Editor:}

Yoshihiro Fukumoto

Received: 11 December 2020

Accepted: 22 January 2021

Published: 26 January 2021

Publisher's Note: MDPI stays neutral with regard to jurisdictional claims in published maps and institutional affiliations.

Copyright: (c) 2021 by the authors. Licensee MDPI, Basel, Switzerland. This article is an open access article distributed under the terms and conditions of the Creative Commons Attribution (CC BY) license (https:// creativecommons.org/licenses/by/ $4.0 /)$.
Abstract: The clinical relevance of polyunsaturated fatty acids (PUFAs) in heart failure remains unclear. The aim of this study was to investigate the association between PUFA levels and the prognosis of patients with heart failure with preserved ejection fraction (HFpEF). This retrospective study included 140 hospitalized patients with acute decompensated HFpEF (median age 84.0 years, $42.9 \%$ men). The patients' nutritional status was assessed, using the geriatric nutritional risk index (GNRI), and their plasma levels of eicosapentaenoic acid (EPA), docosahexaenoic acid (DHA), arachidonic acid (AA), and dihomo-gamma-linolenic acid (DGLA) were measured before discharge. The primary outcome was all-cause mortality. During a median follow-up of 23.3 months, the primary outcome occurred in 37 patients (26.4\%). A Kaplan-Meier analysis showed that lower DHA and DGLA levels, but not EPA or AA levels, were significantly associated with an increase in all-cause death (log-rank; $p<0.001$ and $p=0.040$, respectively). A multivariate Cox regression analysis also revealed that DHA levels were significantly associated with the incidence of all-cause death (HR: 0.16, 95\% CI: 0.06-0.44, $p=0.001$ ), independent of the GNRI. Our results suggest that low plasma DHA levels may be a useful predictor of all-cause mortality and potential therapeutic target in patients with acute decompensated HFpEF.

Keywords: heart failure with preserved ejection fraction; docosahexaenoic acid; geriatric nutritional risk index

\section{Introduction}

Heart failure $(\mathrm{HF})$ is a common and growing public health problem with an estimated prevalence of over 37.7 million cases worldwide [1]. Despite recent developments of HF treatments, including pharmacological and device therapy, HF still results in high mortality and re-hospitalization rates [2]. HF clinically manifests in two modes, which are defined by ventricular function: HF with reduced ejection fraction (HFrEF) and HF with preserved ejection fraction (HFpEF) [3]. Unfortunately, standard pharmacological therapies for HFrEF such as angiotensin-converting enzyme inhibitors and $\beta$-blockers show a lack of efficacy in the treatment of HFpEF [4]. Patients with HFpEF are more likely to be older, female, and have hypertension, renal disease, atrial fibrillation, and malnutrition [5]. Malnutrition, in particular, is a common problem in elderly patients with HFpEF and is a known risk factor for a poor prognosis [6]. 
Polyunsaturated fatty acids (PUFAs) play structural and functional roles as membrane components and precursors of physiologically active substances involved in inflammation [7]. Fish oils, sunflower, safflower, and corn oils are rich in omega-3 PUFAs, while meat from farm animals are rich in omega-6 PUFAs [8]. Omega-3 PUFAs, such as eicosapentaenoic acid (EPA) and docosahexaenoic acid (DHA), and oemga-6 PUFAs, such as arachidonic acid (AA) and dihomo-gamma-linolenic acid (DGLA), have been shown to have opposite effect [9]. It has been reported that AA-derived metabolites are pro-inflammatory, while EPA- and DHA-derived metabolites are pro-resolution/anti-inflammatory [10-12]. Some metabolites have been reported to play a critical role in the development of cardiac hypertrophy and heart failure by regulating inflammatory reactions [12-14]. However, omega-7 and omega-9 monounsaturated fatty acids, such as palmitoleic acid and oleic acid, are components of complex lipids, such as sphingosines and phospholipids, and could interfere with cellular injury [15-17].

Several clinical trials and meta-analysis have demonstrated that omega-3 PUFAs are beneficial for patients with cardiovascular events [18-20]. Regarding the association between omega-3 PUFAs and heart failure, a meta-analysis of seven prospective studies with 176,441 subjects and 5480 cases of HF found a lower risk of HF in patients that took high amounts of marine omega-3 PUFAs [21]. Another study including 6562 patients, in over 13 years, found that plasma EPA levels were significantly lower in HF patients, compared to HF-free patients [22]. Small-scale clinical trials have indicated that omega-3 PUFAs may improve the outcomes of patients with HF [23-26]. However, recent large-scale randomized controlled studies investigating cardiovascular benefit of omega-3 supplementation showed conflicting findings [27,28].

The aim of this study was to investigate the role of PUFAs in the prognosis of patients with acute decompensated HFpEF. In addition, the impact of the patients' nutritional status on the association between PUFAs and their prognosis was evaluated.

\section{Materials and Methods}

\subsection{Study Design and Participants}

This study was a retrospective single-center cohort study. The study protocol was approved by the Institutional Review Board of Mitoyo General Hospital (19CR01-122) and conducted in accordance with the principles of the Declaration of Helsinki. The requirement for informed consent was waived because of the low-risk nature of the study and inability to obtain consent directly from all the study subjects. Instead, we announced this study protocol extensively at Mitoyo General Hospital and on the hospital website (http:/ / mitoyo-hosp.jp) and provided patients with the opportunity to withdraw from the study. We initially enrolled 301 consecutive patients with acute decompensated HFpEF that were not receiving hemodialysis and who were admitted to Mitoyo General Hospital between August 2015 and January 2019. Acute decompensated HF was diagnosed based on the Framingham's criteria. [29]. A diagnosis of HF was made if a patient had at least two major criteria or one major criterion and two minor criteria. The major criteria are acute pulmonary edema, cardiomegaly, hepatojugular reflex, distended neck veins, paroxysmal nocturnal dyspnea, pulmonary rales, and third heart sound. The minor criteria are ankle edema, dyspnea on exertion, hepatomegaly, nocturnal cough, pleural effusion, and tachycardia [29]. HFpEF was defined as HF with a left ventricular ejection fraction $\geq 50 \%$. Patients with HFrEF and those receiving omega-3 PUFA therapy were excluded. Figure 1 shows the flow diagram of this study. Follow-ups were performed by referring to patient electronic medical records, direct contact with the patients' physicians in the outpatient clinic, and telephone interviews with patients or family members. A total of 140 patients were ultimately included in the final analysis. 
453 patients with $\mathrm{HF}$ that are not receiving hemodialysis, who were admitted to Mitoyo General Hospital between August 2015 and January 2019

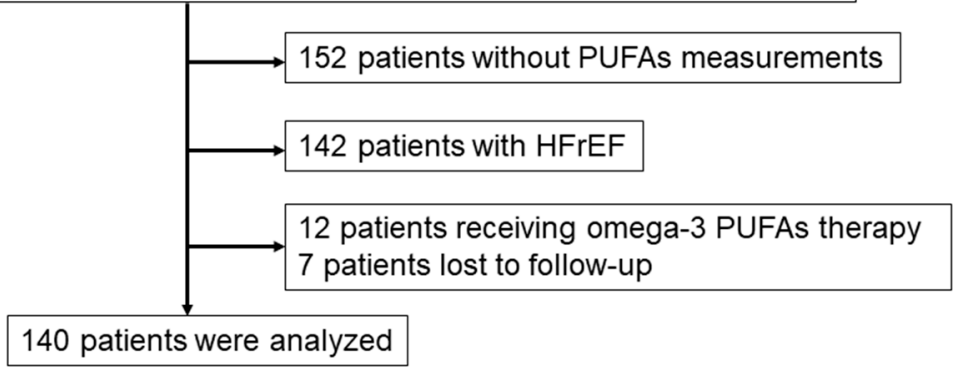

Figure 1. Flowchart of study population. Heart failure (HF) was defined based on the Framingham criteria. Heart failure with reduced ejection fraction (HFrEF); Heart failure with preserved ejection fraction (HFpEF) was defined as $\mathrm{HF}$ with a left ventricular ejection fraction $\geq 50 \%$. PUFAs, polyunsaturated fatty acids.

\subsection{Blood Sampling and Equations}

Whole blood samples were collected within $24 \mathrm{~h}$ of admission. Approximately $20 \mathrm{~mL}$ of blood was collected by venipuncture and separated into tubes containing clot activator, gel serum separator, ethylenediaminetetraacetic acid dipotassium, and heparin sodium. Plasma levels of EPA, DHA, AA, and DGLA were measured by using gas chromatography (SRL Inc., Tokyo, Japan) [30]. Routine laboratory tests were performed, using an automated analyzer, at Mitoyo General Hospital. The estimated glomerular filtration rate (eGFR) was calculated based on the Japanese equation that uses serum creatinine level, age, and sex as follows: eGFR $\left(\mathrm{mL} / \mathrm{min} / 1.73 \mathrm{~m}^{2}\right)=194 \times$ serum creatinine ${ }^{-1.094} \times$ age $^{-0.287}$ (for females $=\times 0.739)$ [31]. The geriatric nutritional risk index $($ GNRI) was calculated as follows, using the serum albumin level, body weight, and height obtained on admission: GNRI $=14.89 \times$ serum albumin $(\mathrm{g} / \mathrm{dL})+41.7 \times($ actual body weight $/$ ideal body weight $)$. GNRI is a nutrition-related risk index that makes it possible to classify patients according to a risk of morbidity and mortality, and the GNRI $\geq 98$ means no nutritional-related risk [32]. The ideal body weight in the present study was calculated by using a body mass index of $22 \mathrm{~kg} / \mathrm{m}^{2}$.

\subsection{Assessment of Additional Risk Factors}

Hypertension was defined as having a seated blood pressure $>140 / 90 \mathrm{mmHg}$ or undergoing current treatment with antihypertensive medications. Diabetes mellitus was defined as having a previous diagnosis of diabetes mellitus in the medical records, a hemoglobin A1C (national glycohemoglobin standardization program calculation) level $\geq 6.5 \%$, or receiving treatment with oral antidiabetic agents or insulin. Dyslipidemia was defined as one or more of the following characteristics: $\geq 150 \mathrm{mg} / \mathrm{dL}$ serum triglyceride, $<40 \mathrm{mg} / \mathrm{dL}$ highdensity lipoprotein cholesterol (HDL-cholesterol), $\geq 140 \mathrm{mg} / \mathrm{dL}$ low-density lipoprotein cholesterol (LDL-cholesterol), or current treatment with a lipid-lowering drug. Smoking status was defined as "currently smoking".

\subsection{Study Outcomes}

The primary endpoint was all-cause mortality. Furthermore, as an ad hoc analysis, patients were divided into four groups, based on the median DHA level and median GNRI, so that the association between the primary endpoint and each group could be evaluated. The secondary endpoints were cardiac death and re-hospitalization for HF.

\subsection{Statistical Analyses}

The results are presented as the mean \pm standard deviation when they are normally distributed, and as the median and interquartile range (IQR) when they are non-normally distributed. The normality of distribution was determined by the Kolmogorov-Smirnov 
test. Differences between the groups were analyzed by using the unpaired Student's t-test or Mann-Whitney U test for continuous variables, and the chi-squared test or Fisher's exact test for dichotomous variables, as appropriate. For the survival analyses, KaplanMeier survival plots were constructed by dividing the patients' PUFA levels on admission into two groups, according to the median values, and log-rank testing was performed to study the influence of PUFA levels on primary and secondary endpoints. To evaluate the influence of PUFA levels on the primary endpoint, Cox proportional-hazards regression models were used to estimate the hazard ratio (HR) and 95\% confidence interval (CI). To avoid overfitting, variables that were included in the principal multivariate models were adjusted for age, sex, hypertension, dyslipidemia, diabetes mellitus, and GNRI. All the tests were two-tailed, and a value of $p<0.05$ was considered statistically significant. All the analyses were performed by using IBM SPSS statistics version 24.0 (IBM Corp., Armonk, NY, USA).

\section{Results}

\subsection{Baseline Characteristics}

Table 1 shows the baseline characteristics of the patients in this study and a comparison of those characteristics between the patients with and without primary endpoints. The median age of all the patients was 84.0 years, $42.9 \%$ were male, and $56.4 \%$ had atrial fibrillation. The prevalence of hypertension and diabetes mellitus within the group of patients was $90.0 \%$ and $22.9 \%$, respectively.

During the median follow-up of 23.3 months, 37 (26.4\%) of the patients exhibited the primary endpoint. Patients experiencing the primary endpoint were older; had lower BMI and GNRI values; had a lower prevalence of hypertension and dyslipidemia; had lower statin use; and had lower hemoglobin, albumin, HDL-cholesterol, and LDL-cholesterol levels than those who did not experience the primary endpoint. No significant differences in the prevalence of atrial fibrillation, prior hospitalization for HF, or medication use, except for statins, were observed between the two groups. The median levels of EPA, DHA, DGLA, and AA, as well as the ratio of EPA to AA (EPA/AA), DHA to AA (DHA/AA), and AA + DGLA to EPA + DHA (AA + DGLA/EPA + DHA), on admission were $46.6 \mu \mathrm{g} / \mathrm{mL}$, $116.1 \mu \mathrm{g} / \mathrm{mL}, 23.6 \mu \mathrm{g} / \mathrm{mL}, 159.8 \mu \mathrm{g} / \mathrm{mL}, 0.26,0.74$, and 1.15, respectively. The levels of DHA, DGLA, and AA for the patients with adverse events were significantly lower than for those patients without adverse events. The levels of EPA, EPA/AA, DHA/AA, and AA+DGLA/EPA+DHA did not differ between the two groups.

\subsection{Cumulative Event Rates Based on PUFA Levels}

The Kaplan-Meier analyses showed that lower levels of DHA and DGLA on admission were significantly associated with the incidence of adverse events (log-rank; $p<0.001$ and $p=0.040$, respectively) (Figure 2B,D). However, the EPA and AA levels and the EPA/AA, DHA/AA, and AA + DGLA/ EPA + DHA were not associated (log-rank; $p=0.051$, $p=0.154, p=0.649, p=0.887, p=0.712$, respectively) (Figure 2A,C,E-G).

\subsection{Univariate and Multivariate Analyses of Parameters Contributing to the Primary and Secondary Endpoints}

The univariate Cox regression analyses showed that age, body mass index, statin use, hemoglobin, albumin, LDL-cholesterol, GNRI, DGLA level, and DHA level were associated with the incidence of the primary endpoint (Table 2). The multivariate Cox regression analyses revealed that patients with high DHA levels was significantly associated with a low incidence of the primary endpoint after an adjustment for age, sex, hypertension, dyslipidemia, diabetes mellitus, and GNRI (HR: 0.16, 95\% CI: 0.06-0.44, $p=0.001$ ). However, the DGLA level was not significantly associated with the primary endpoint after an adjustment for confounding variables. 
Table 1. Baseline characteristics according to the presence or absence of the primary endpoint.

\begin{tabular}{|c|c|c|c|c|}
\hline \multirow[b]{2}{*}{ Variables } & \multirow[b]{2}{*}{ All $(n=140)$} & \multicolumn{2}{|c|}{ Primary Endpoint } & \multirow[b]{2}{*}{$p$} \\
\hline & & Absent $(n=103)$ & Present $(n=37)$ & \\
\hline Men & $60(42.9)$ & $40(38.8)$ & $20(54.1)$ & 0.110 \\
\hline Age, years & $84.0(77.0,88.0)$ & $82.0(76.0,88.0)$ & $86.0(83.0,89.0)$ & 0.018 \\
\hline Body mass index, $\mathrm{kg} / \mathrm{m}^{2}$ & $23.3(20.4,26.6)$ & $22.4(20.8,27.5)$ & $22.1(19.9,24.1)$ & 0.008 \\
\hline Hypertension & $126(90.0)$ & $96(93.2)$ & $30(81.1)$ & 0.035 \\
\hline Diabetes Mellitus & $32(22.9)$ & $22(21.4)$ & $10(27.0)$ & 0.485 \\
\hline Dyslipidemia & $45(32.1)$ & $38(36.9)$ & $7(18.9)$ & 0.045 \\
\hline Current smoker & $49(35.0)$ & $33(32.0)$ & $16(43.2)$ & 0.223 \\
\hline Prior hospitalization for heart failure & $19(13.6)$ & $13(12.6)$ & $6(16.2)$ & 0.587 \\
\hline Ischemic heart disease & $18(12.9)$ & $15(14.6)$ & $3(8.1)$ & 0.318 \\
\hline Atrial fibrillation & $79(56.4)$ & $59(57.3)$ & $20(54.1)$ & 0.736 \\
\hline Prior PCI & $14(10.0)$ & $12(11.7)$ & $2(5.4)$ & 0.281 \\
\hline Prior $\mathrm{CABG}$ & $5(3.6)$ & $5(4.9)$ & $0(0)$ & 0.175 \\
\hline Valve repair/placement & $14(10.0)$ & $12(11.7)$ & $2(5.4)$ & 0.281 \\
\hline Pacemaker implantation & $14(10.0)$ & $7(6.8)$ & $7(18.9)$ & 0.035 \\
\hline \multicolumn{5}{|l|}{ Medications } \\
\hline ACEIs/ARBs & $55(39.3)$ & $43(41.7)$ & $12(32.4)$ & 0.323 \\
\hline$\beta$-blockers & $48(34.3)$ & $39(37.9)$ & $9(24.3)$ & 0.139 \\
\hline CCBs & $72(51.4)$ & $55(53.4)$ & $17(45.9)$ & 0.440 \\
\hline Loop diuretics & $79(56.4)$ & $54(52.4)$ & $25(67.6)$ & 0.113 \\
\hline MRAs & $26(18.6)$ & $16(15.5)$ & $10(27.0)$ & 0.125 \\
\hline Antiplatelets & $31(22.1)$ & $27(26.2)$ & $4(10.8)$ & 0.053 \\
\hline Oral antidiabetic agents & $22(15.7)$ & $17(16.5)$ & $5(13.5)$ & 0.671 \\
\hline Statins & $35(25.0)$ & $31(30.1)$ & $4(10.8)$ & 0.020 \\
\hline Anticoagulants & $22(15.7)$ & $46(44.7)$ & $17(45.9)$ & 0.894 \\
\hline \multicolumn{5}{|l|}{ Laboratory findings } \\
\hline Hemoglobin (g/dL) & $11.0 \pm 2.09$ & $11.2 \pm 2.10$ & $10.3 \pm 1.94$ & 0.017 \\
\hline Creatinine $(\mathrm{mg} / \mathrm{dL})$ & $1.08(0.82,1.62)$ & $1.03(0.83,1.56)$ & $1.27(0.79,1.75)$ & 0.364 \\
\hline $\mathrm{eGFR}\left(\mathrm{ml} / \mathrm{min} / 1.73 \mathrm{~m}^{2}\right)$ & $42.2(29.0,56.0)$ & $43.0(29.0,55.0)$ & $41.0(26.2,59.6)$ & 0.530 \\
\hline Albumin $(\mathrm{g} / \mathrm{dL})$ & $3.6(3.2,3.9)$ & $3.6(3.4,3.9)$ & $3.4(2.9,3.7)$ & 0.001 \\
\hline hsCRP (mg/dL) & $0.43(0.17,1.45)$ & $0.36(0.15,1.08)$ & $0.86(0.24,1.59)$ & 0.581 \\
\hline $\mathrm{BNP}(\mathrm{pg} / \mathrm{mL})$ & $453.0(260.4,699.0)$ & $464.0(246.8,739.4)$ & $411.0(269.9,659.5)$ & 0.107 \\
\hline Troponin I (pg/mL) & $32.7(15.2,84.7)$ & $33.0(14.3,84.7)$ & $28.9(16.3,70.8)$ & 0.520 \\
\hline Hemoglobin A1C (\%) & $5.9(5.6,6.5)$ & $5.9(5.6,6.5)$ & $5.9(5.6,6.6)$ & 0.871 \\
\hline Triglycerides (mg/dL) & $76(57,98)$ & $78(62,98)$ & $67(50,94)$ & 0.110 \\
\hline HDL-C (mg/dL) & $46 \pm 14.4$ & $48 \pm 13.8$ & $41 \pm 15.5$ & 0.047 \\
\hline LDL-C (mg/dL) & $97 \pm 36.7$ & $102 \pm 37.1$ & $81 \pm 30.8$ & 0.014 \\
\hline $\mathrm{EPA}(\mu \mathrm{g} / \mathrm{mL})$ & $46.6(30.7,64.2)$ & $48.0(31.9,67.8)$ & $39.6(28.0,55.0)$ & 0.076 \\
\hline DHA $(\mu \mathrm{g} / \mathrm{mL})$ & $116.1(96.7,144.9)$ & $126.7(99.1,149.8)$ & $102.8(94.3,119.5)$ & 0.009 \\
\hline $\mathrm{AA}(\mu \mathrm{g} / \mathrm{mL})$ & $159.8(133.8,194.5)$ & $167.1(144.2,195.0)$ & $139.1(110.5,180.7)$ & 0.001 \\
\hline DGLA $(\mu \mathrm{g} / \mathrm{mL})$ & $23.6(19.6,30.5)$ & $24.2(20.1,32.5)$ & $22.2(18.4,27.1)$ & 0.019 \\
\hline $\mathrm{EPA} / \mathrm{AA}$ & $0.26(0.20,0.40)$ & $0.27(0.20,0.40)$ & $0.26(0.21,0.39)$ & 0.812 \\
\hline $\mathrm{DHA} / \mathrm{AA}$ & $0.74(0.62,0.89)$ & $0.74(0.60,0.90)$ & $0.78(0.63,0.88)$ & 0.287 \\
\hline $\mathrm{AA}+\mathrm{DGLA} / \mathrm{EPA}+\mathrm{DHA}$ & $1.15(0.90,1.38)$ & $1.15(0.90,1.42)$ & $1.14(0.95,1.32)$ & 0.481 \\
\hline GNRI & $97.7 \pm 12.03$ & $99.9 \pm 11.59$ & $90.8 \pm 10.84$ & $<0.001$ \\
\hline
\end{tabular}

Categorical variables are presented as number of patients (\%). Continuous variables are presented as the mean \pm standard deviation or median (interquartile range). PCI, percutaneous coronary intervention; CABG, coronary artery bypass grafting; ACEs, angiotensinconverting enzyme inhibitors; ARBs, angiotensin II receptor blockers; CCBs, calcium channel blockers; MRAs, mineralocorticoid receptor antagonists; eGFR, estimated glomerular filtration rate; hsCRP, high-sensitivity C-reactive protein; BNP, brain natriuretic peptide; HDL-C, high-density lipoprotein cholesterol; LDL-C, low-density lipoprotein cholesterol; EPA, eicosapentaenoic acid; DHA, docosahexaenoic acid; DGLA, dihomo-gamma-linolenic acid; AA, arachidonic acid; DHA/AA, ratio of DHA to AA; AA+DGLA/EPA+DHA, ratio of AA+DGLA to EPA+DHA; GNRI, geriatric nutritional risk index. 
A

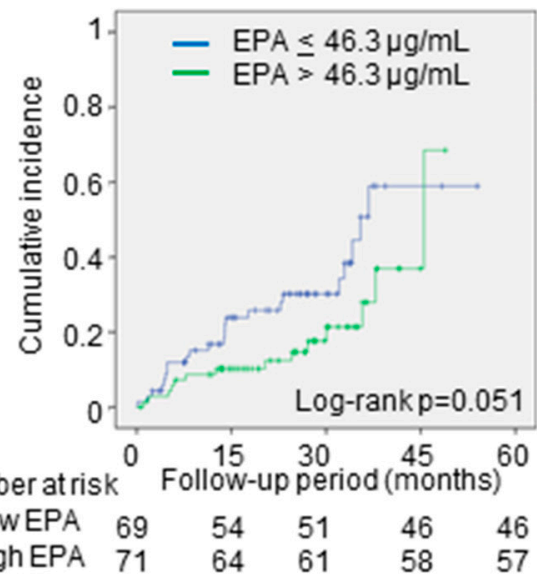

C

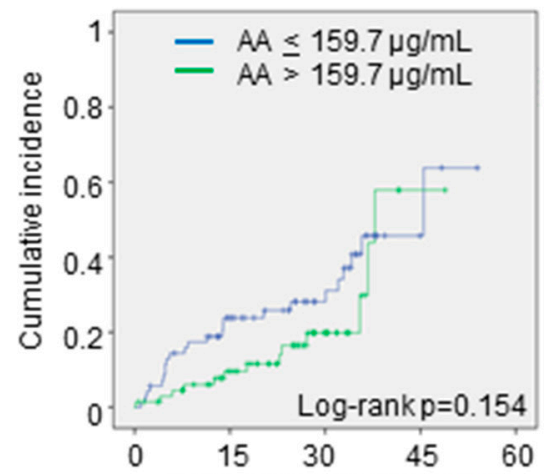

Number at risk Follow-up period (months)

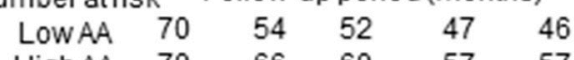

$\begin{array}{llllll}\text { High AA } & 70 & 66 & 60 & 57 & 57\end{array}$

E

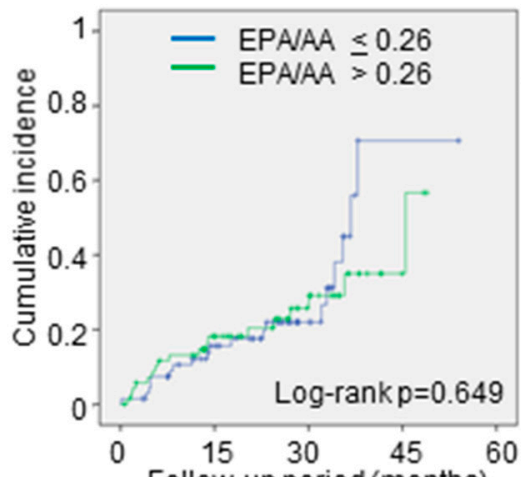

Number at risk

$\begin{array}{llllll}\text { LOWEPAIAA } & 69 & 59 & 46 & 50 & 50\end{array}$

$\begin{array}{llllll}\text { High EPAJAA } & 71 & 59 & 56 & 54 & 53\end{array}$

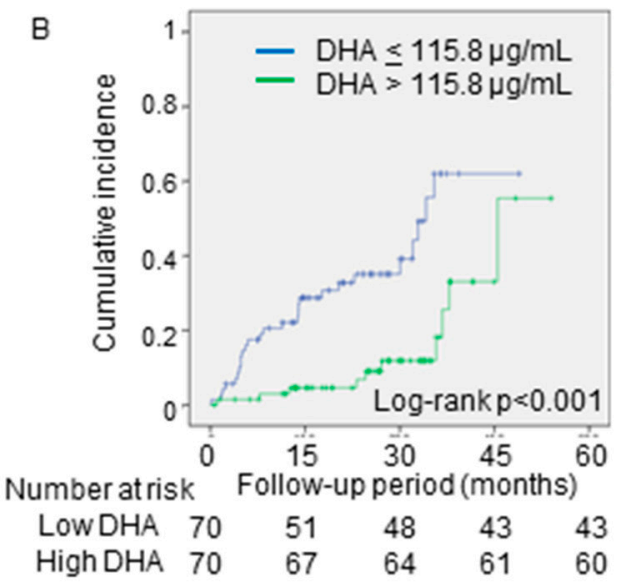

D

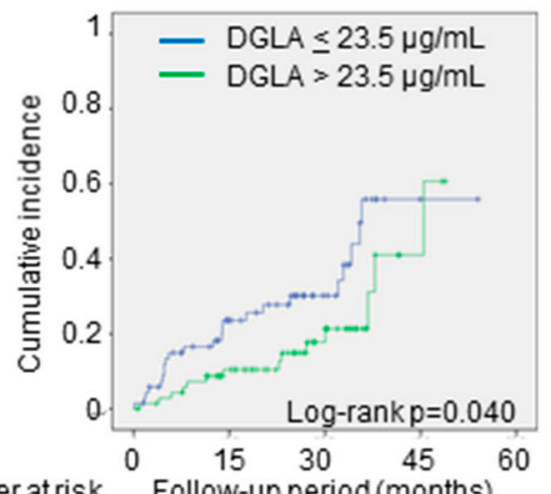

Number atrisk Follow-up period (months)

$\begin{array}{llllll}\text { LOWDGLA } & 69 & 54 & 51 & 46 & 46\end{array}$

$\begin{array}{llllll}\text { High DGLA } & 71 & 64 & 61 & 58 & 57\end{array}$

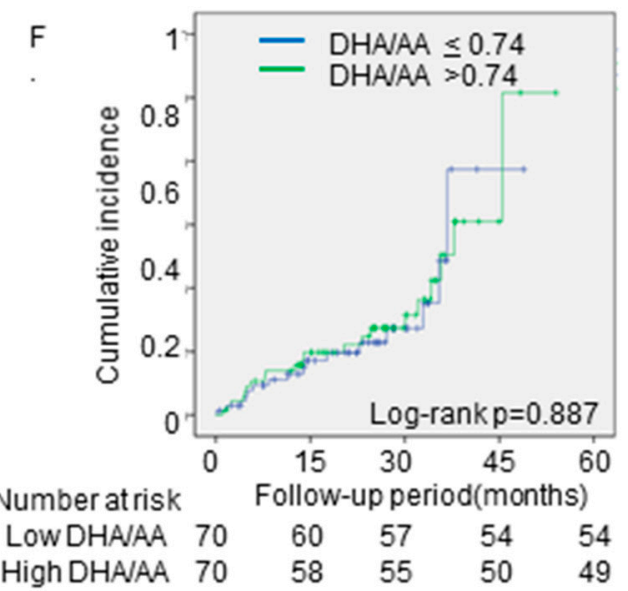

Figure 2. Cont. 


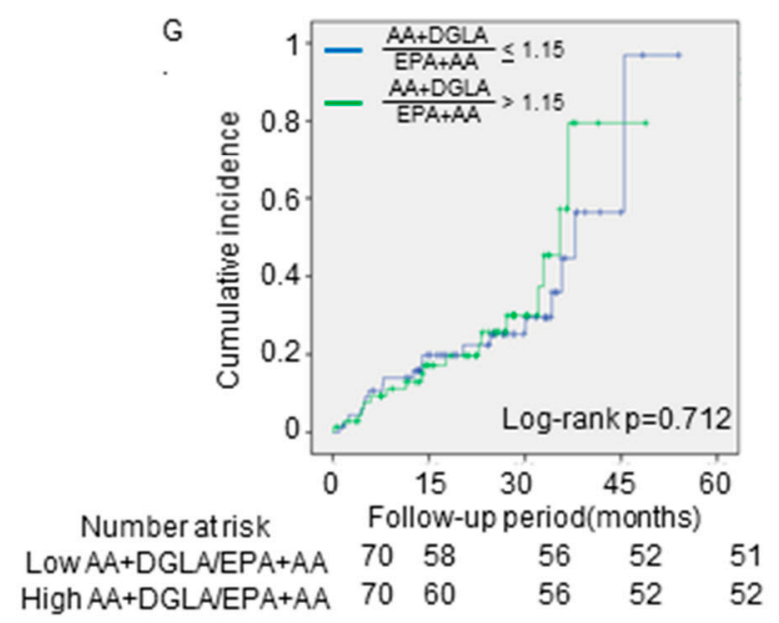

Figure 2. The associations between the primary outcomes and PUFA levels. The cumulative incidences of the primary endpoint (all-cause death) were estimated by using the Kaplan-Meier method. The patients were divided into two groups, based on the median levels of (A) EPA, (B) DHA, (C) AA, (D) DGLA, (E) EPA/AA, (F) DHA/AA, and (G) $\mathrm{AA}+\mathrm{DGLA} / \mathrm{EPA}+\mathrm{DHA}$. Log-rank testing was performed to study the influence of PUFA levels on primary endpoint. EPA, eicosapentaenoic acid; DHA, docosahexaenoic acid; DGLA, dihomo-gamma-linolenic acid; AA, arachidonic acid; $\mathrm{EPA} / \mathrm{AA}$, ratio of EPA to AA; DHA/AA, ratio of DHA to AA; AA + DGLA/EPA + DHA; ratio of AA + DGLA to $\mathrm{EPA}+\mathrm{DHA}$.

Table 2. The association between PUFAs and the primary endpoint analyzed with Cox proportional hazards models.

\begin{tabular}{|c|c|c|c|c|c|c|c|c|c|}
\hline & \multicolumn{3}{|c|}{ Univariate } & \multicolumn{3}{|c|}{ Multivariate-1 } & \multicolumn{3}{|c|}{ Multivariate-2 } \\
\hline & HR & $95 \% \mathrm{CI}$ & $p$ & HR & $95 \% \mathrm{CI}$ & $p$ & HR & $95 \% \mathrm{CI}$ & $p$ \\
\hline $\begin{array}{c}\text { Age, } \\
\text { per } 1 \text { year }\end{array}$ & 1.06 & $1.01-1.11$ & 0.009 & 1.05 & 0.99-1.10 & 1.102 & 1.06 & $1.00-1.13$ & 0.042 \\
\hline Male & 1.76 & $0.92-3.37$ & 0.087 & 1.76 & $0.81-3.83$ & 0.155 & 1.98 & $0.91-4.29$ & 0.083 \\
\hline $\begin{array}{l}\text { Body mass index, } \\
\text { per } 1.0 \mathrm{~kg} / \mathrm{m}^{2}\end{array}$ & 0.90 & $0.82-0.98$ & 0.017 & - & - & - & - & - & - \\
\hline Hypertension & 0.52 & $0.26-1.06$ & 0.071 & 0.65 & $0.26-1.59$ & 0.342 & 1.13 & $0.45-2.82$ & 0.793 \\
\hline Dyslipidemia & 0.45 & $0.20-1.03$ & 0.060 & 0.72 & $0.25-2.12$ & 0.549 & 0.66 & $0.23-1.91$ & 0.441 \\
\hline Diabetes mellitus & 1.54 & $0.74-3.21$ & 0.249 & 1.99 & $0.87-4.58$ & 0.104 & 1.86 & $0.78-4.46$ & 0.164 \\
\hline Statin use & 0.34 & $0.12-0.95$ & 0.040 & - & - & - & - & - & - \\
\hline $\begin{array}{l}\text { Hemoglobin, } \\
\text { per } 1.0 \mathrm{mg} / \mathrm{dL}\end{array}$ & 0.82 & $0.70-0.96$ & 0.013 & - & - & - & - & - & - \\
\hline $\begin{array}{c}\text { Albumin, } \\
\text { per } 1.0 \mathrm{~g} / \mathrm{dL}\end{array}$ & 0.34 & $0.18-0.63$ & 0.001 & - & - & - & - & - & - \\
\hline $\begin{array}{c}\text { HDL-C, } \\
\text { per } 1 \mathrm{mg} / \mathrm{dL}\end{array}$ & 0.96 & $0.93-1.00$ & 0.054 & - & - & - & - & - & - \\
\hline $\begin{array}{c}\text { LDL-C, } \\
\text { per } 1 \mathrm{mg} / \mathrm{dL}\end{array}$ & 0.98 & $0.96-0.99$ & 0.004 & - & - & - & - & - & - \\
\hline $\begin{array}{l}\text { GNRI, } \\
\text { per } 1 \text { index }\end{array}$ & 0.94 & $0.91-0.97$ & $<0.001$ & 0.95 & $0.91-0.99$ & 0.010 & 0.95 & $0.91-0.98$ & 0.002 \\
\hline High DGLA & 0.50 & $0.26-0.98$ & 0.044 & 1.02 & $0.47-2.19$ & 0.969 & - & - & - \\
\hline High AA & 0.61 & $0.31-1.21$ & 0.158 & - & - & - & - & - & - \\
\hline High EPA & 0.52 & $0.27-1.01$ & 0.055 & - & - & - & - & - & - \\
\hline High DHA & 0.25 & $0.12-0.53$ & $<0.001$ & - & - & - & 0.16 & $0.06-0.44$ & $<0.001$ \\
\hline High EPA/AA & 0.86 & $0.45-1.65$ & 0.650 & - & - & - & & - & \\
\hline High DHA/AA & 1.05 & $0.54-2.02$ & 0.887 & - & - & - & & - & \\
\hline $\begin{array}{c}\text { High AA + } \\
\text { DGLA / } \\
\text { EPA + DHA }\end{array}$ & 1.13 & $0.59-2.17$ & 0.712 & - & - & - & & - & \\
\hline
\end{tabular}

The multivariate model-1 and model-2 were adjusted for age, sex, hypertension, dyslipidemia, diabetes mellitus, and GNRI. HR, hazard ratio; CI, confidence interval; GNRI, geriatric nutritional risk index; EPA, eicosapentaenoic acid; DHA, docosahexaenoic acid; DGLA, dihomogamma-linolenic acid; AA, arachidonic acid. EPA/AA, ratio of EPA to AA; DHA/AA, ratio of DHA to AA; AA + DGLA/EPA + DHA; ratio of AA + DGLA to EPA + DHA. 
As an ad hoc analysis, the patients were divided into four groups, based on the median DHA and GNRI values. As shown in Figure 3, the low-GNRI and low-DHA groups showed the greatest incidence of the primary endpoint, compared to the other groups (log-rank; $p<0.001$ ). In the multivariate Cox regression analyses, the low-GNRI and low-DHA groups had a significantly higher risk of the primary endpoint, compared with the high-GNRI and high-DHA groups, after an adjustment of age and sex (HR: 8.48, 95\% CI: 2.47-29.07, $p=0.001$ ) (Table 3).

The secondary endpoints occurred in 63 patients (cardiac death $(n=15)$ and rehospitalization for HF $(n=480)$ ). As shown in Figure 4 , none of the PUFA levels was associated with the secondary endpoints.

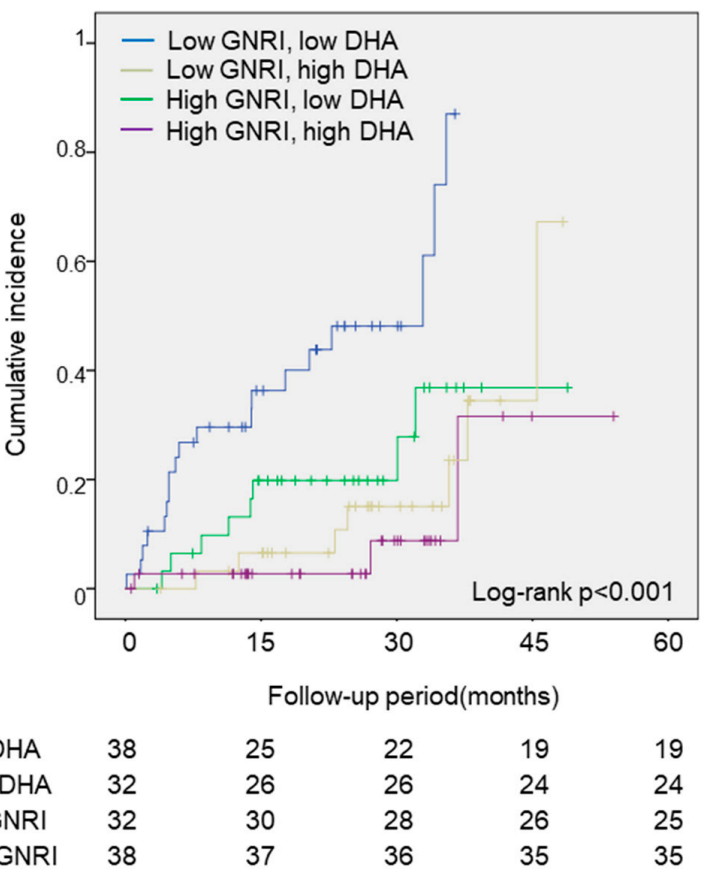

Figure 3. The associations between the primary outcomes and the DHA and GNRI values. The cumulative incidences of the primary endpoint (all-cause death) were estimated by using the KaplanMeier method. Log-rank testing was performed to study the influence of PUFA levels on primary endpoint. The patients were divided into four groups, based on the median DHA and GNRI values. DHA, docosahexaenoic acid; GNRI, geriatric nutritional risk index.

Table 3. The association between the DHA and GNRI values and primary endpoints analyzed with Cox proportional hazards models.

\begin{tabular}{|c|c|c|c|}
\hline & & ivariate $A n_{c}$ & \\
\hline Variables & HR & $95 \% \mathrm{CI}$ & $P$ \\
\hline Age, per 1-year & 1.07 & $1.02-1.13$ & 0.006 \\
\hline Male & 1.67 & $0.87-3.22$ & 0.123 \\
\hline $\begin{array}{l}\text { High DHA and high } \\
\text { GNRI }\end{array}$ & & Reference & \\
\hline $\begin{array}{l}\text { High DHA and low } \\
\text { GNRI }\end{array}$ & 1.14 & $0.28-4.64$ & 0.858 \\
\hline $\begin{array}{l}\text { Low DHA and high } \\
\text { GNRI }\end{array}$ & 3.03 & $0.80-11.48$ & 0.104 \\
\hline $\begin{array}{l}\text { Low DHA and low } \\
\text { GNRI }\end{array}$ & 8.48 & $2.47-29.07$ & 0.001 \\
\hline
\end{tabular}




\section{A}

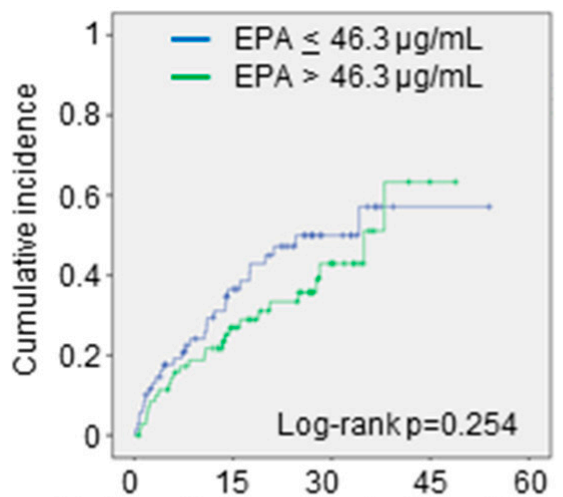

Number at risk Follow-up period (months)

$\begin{array}{llllll}\text { LoWEPA } & 69 & 46 & 40 & 39 & 39\end{array}$

$\begin{array}{llllll}\text { High EPA } & 71 & 53 & 47 & 45 & 45\end{array}$

C

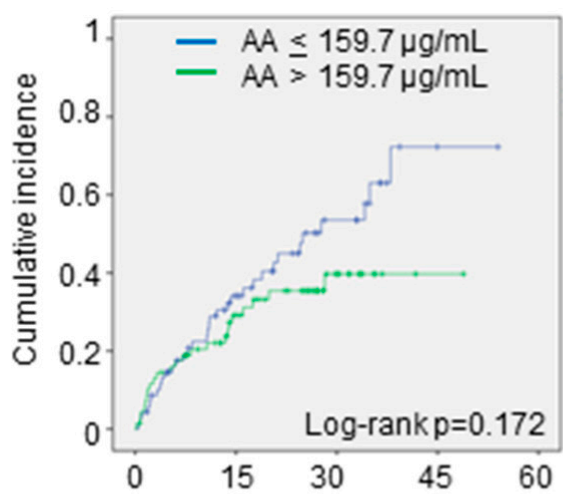

Number at risk Follow-up period (months)

$\begin{array}{llllll}\text { High AA } & 70 & 51 & 47 & 47 & 47\end{array}$

E

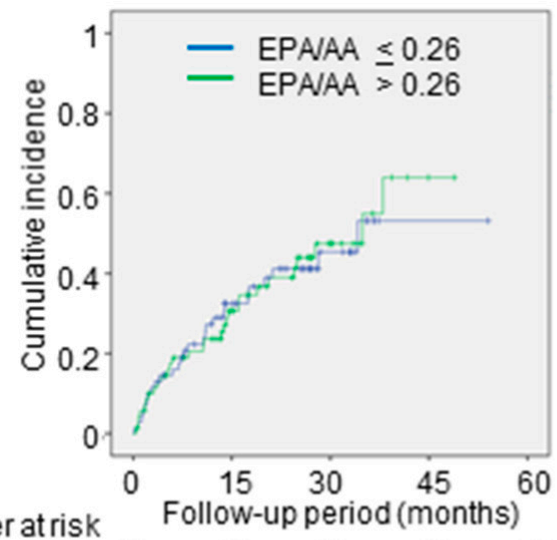

Number at risk

Follow-up period (months)

$\begin{array}{llllll}\text { LowEPANAA } & 69 & 59 & 46 & 50 & 50 \\ \text { High EPANAA } & 71 & 59 & 56 & 54 & 53\end{array}$

B

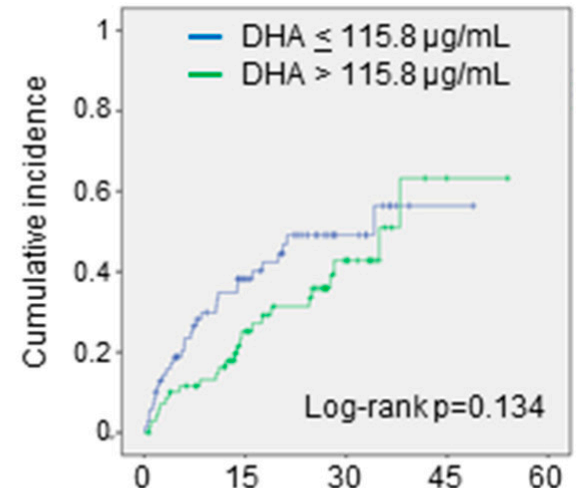

Number at risk

$\begin{array}{llllll}\text { LowDHA } & 70 & 45 & 40 & 39 & 39 \\ \text { High DHA } & 70 & 54 & 47 & 45 & 45\end{array}$

D

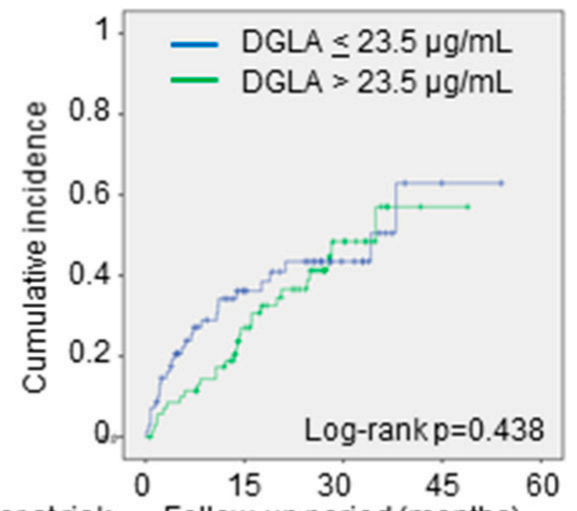

Number at risk Follow-up period (months)

$\begin{array}{llllll}\text { LowDGLA } & 70 & 48 & 45 & 45 & 45 \\ \text { High DGLA } & 70 & 51 & 42 & 39 & 39\end{array}$

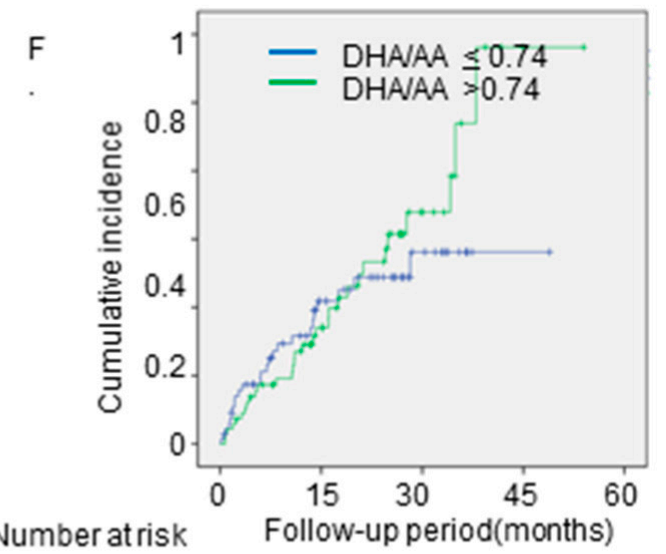

$\begin{array}{llllll}\text { LoWDHANAA } & 70 & 60 & 57 & 54 & 54 \\ \text { High DHAIAA } & 70 & 58 & 55 & 50 & 49\end{array}$

Figure 4. Cont. 


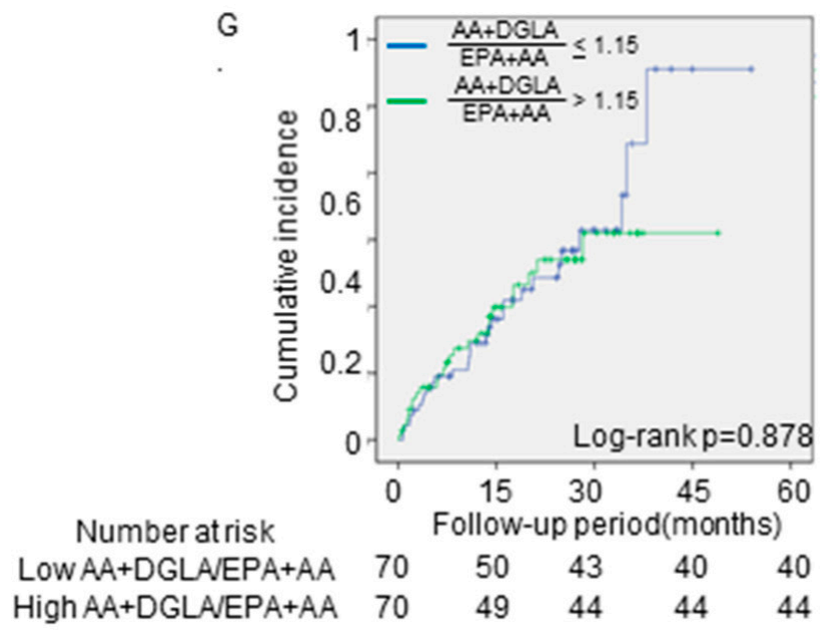

Figure 4. The associations between the secondary outcomes and PUFA levels. The cumulative incidences of the secondary endpoints (cardiac death and re-hospitalization for heart failure) were estimated by using the Kaplan-Meier method. Log-rank testing was performed to study the influence of PUFA levels on primary endpoint. The patients were divided into two groups, based on the median levels of (A) EPA, (B) DHA, (C) AA, (D) DGLA, and (E) EPA/AA, (F) DHA/AA, and (G) AA + DGLA/EPA + DHA. PUFA, polyunsaturated fatty acid; EPA, eicosapentaenoic acid; DHA, docosahexaenoic acid; AA, arachidonic acid; DGLA, dihomo-gamma-linolenic acid; EPA/AA, ratio of EPA to AA; DHA/AA, ratio of DHA to AA; $\mathrm{AA}+\mathrm{DGLA} / \mathrm{EPA}+\mathrm{DHA}$; ratio of AA + DGLA to EPA + DHA.

\section{Discussion}

The data from the present study showed that the acute decompensated HFpEF patients with lower plasma DHA levels had a significantly higher incidence of all-cause death, independent of GNRI. These findings suggest that plasma DHA levels are an important factor associated with prognosis, regardless of the nutritional status of patients with acute decompensated HFpEF. This suggests that measuring plasma DHA levels may be useful for the detection of high-risk patients hospitalized with HFpEF.

Several studies have shown the association between circulating concentrations of PUFAs and the incidence of HF. A previous cohort study, which included 2735 adults in the Cardiovascular Health Study from 1992 to 2006, reported that the total concentrations of omega-3 fatty acid were associated with the incidence of primary congestive HF [19]. A recent report from the Multi-Ethnic Study of Atherosclerosis (MESA) trial indicated that higher plasma EPA levels were significantly associated with a reduced risk of HF (for both reduced and preserved EF) [22]. In addition, regarding the association between PUFAs and the prognosis of patients with acute decompensated HF, a study showed that decreased plasma levels of DHA, DGLA, and AA were independently associated with long-term mortality in patients with acute decompensated HF [33]. Other studies have shown that lower omega-6 PUFAs levels were related to worse clinical outcomes in patients with acute decompensated HF $[34,35]$. However, most of the patients included in these studies had HFrEF. Thus, to the best of our knowledge, this is the first study to evaluate the correlation between PUFA levels and the prognosis of patients with HFpEF.

This study showed that lower DHA levels, but not EPA levels, were independently associated with all-cause mortality in patients with acute decompensated HFpEF. PUFAs play an important role in cellular membrane function [36]. While DHA is abundant in the cell membranes of cardiomyocytes [25], EPA is scarce. This difference may contribute to the distinct effects that DHA and EPA have on cardiac health. It should be noted, however, that while DHA can be obtained from the diet, it can also be synthesized from EPA [37]. In fact, the data from MESA suggested that EPA was more important than DHA for HF [19]. Therefore, any interpretation of the differences between the effects of DHA and EPA on the prognosis of HFpEF patients should be made with caution. 
Although the present study showed a relationship between lower plasma DHA levels and a higher incidence of all-cause death, there was no significant association between DHA levels and composite events of cardiac death and re-hospitalization for HF. According to a Japanese cohort study called the Chronic Heart Failure Analysis and Registry in the Tohoku (CHART), the temporal trend in the mode of death in symptomatic HF has changed. As the prevalence of HFpEF in symptomatic HF increased from CHART-1 (2000-2005) to CHART-2 (2006-2010), the proportion of non-cardiac deaths increased from $23 \%$ in CHART-1 to 40\% in CHART-2 [5]. In this study [5], those factors that were significantly associated with all-cause death were reported to be advanced age, low BMI, high systolic blood pressure, and absence of dyslipidemia. This is in line with our data shown in Table 1. Patients with HFpEF had more comorbidities than HFrEF patients, and noncardiac deaths occurred more frequently in HFpEF patients than in HFrEF patients [38].

Thus, the characteristics inherent to HFpEF patients specifically may be involved in the significant impact that DHA levels have on all-cause death, as opposed to cardiac death or re-hospitalization for HF.

Malnutrition is frequently observed and an important risk factor for poor outcomes in patients with HF. The GNRI is a simple and objective nutritional index, and a GNRI $<92$ is generally used to evaluate the increased risk of morbidity and mortality in hospitalized elderly patients [21]. In our study, patients with the primary endpoint had an average GNRI of 90.8, suggesting a poor nutritional status. Although the patients with the primary endpoint also showed lower omega-3 PUFA levels, which were affected by oral intake, the Cox regression analyses revealed that the impact of the DHA levels on the patients prognoses was independent of the GNRI. Even in the patients with a poor nutritional status, lower DHA levels were shown to be an independent predictor of all-cause mortality in HFpEF patients.

Inflammation is a normal process that is part of the body's defense and tissue-healing mechanism. However, excessive or unresolved inflammation can lead to uncontrolled tissue injury, and disease. Omega-6-derived metabolites, such as prostaglandins and leukotrienes, have pro-inflammatory effects, while omega-3-derived metabolites, such as resolvins and protectins, have anti-inflammatory and pro-resolving effects [10,11]. In this context, several clinical studies showed that the ratio of omega- 3 to omega-6 PUFAs is a powerful predictor of heart disease [39-41]. Therefore, active screening of PUFAs would be beneficial in identifying patients at high risk of cardiovascular disease.

The GISSI-HF (Gruppo Italiano per lo Studio della Sopravvivenza nell'Infarto Miocardico Heart Failure) trial was a large-scale, placebo-controlled, randomized study that showed that $1 \mathrm{~g}$ daily of omega- 3 fatty acid administration reduced the risk of all-cause death by $9 \%$ and the risk of hospitalization due to cardiovascular reasons by $8 \%$ in patients with chronic heart failure [42]. Other clinical trials have indicated that omega-3 fatty acids might improve outcomes in patients with HF [23-26]. In addition, animal studies have shown that omega-3 fatty acids, including EPA and DHA, at supraphysiological levels, preserve left ventricular function and prevent interstitial fibrosis in a mouse model of pressure overload-induced HF $[39,43,44]$. Despite these potential benefits, the use of omega-3 fatty acids in patients with HF remains controversial. Future large-scale randomized clinical trials to investigate the benefit of high dosages of omega-3 fatty acids, on top of the guideline-directed medical therapy for patients with documented overt HF, will be needed.

This study had several limitations. First, the study was conducted in a single center, the sample size was small, and the follow-up period was short. Therefore, it may be difficult to generalize these results. Second, the PUFAs were not measured in the cell membrane. PUFAs in the cell membrane have been reported to be direct precursors of pro- and antiinflammatory eicosanoids. However, it has also been reported that cell-membrane PUFAs are significantly correlated with serum PUFAs in the Japanese population [30]. Third, food intake is associated with blood levels of PUFAs; however, measurement of dietary intake by using a frequency food questionnaire was not performed in this study. Moreover, the multivariate cox regression model included a limited number of variates to avoid statistical 
overfitting, because of the small number of the primary outcome. Therefore, large-scale studies will be needed to confirm our findings. Finally, the study was an observational study, so the causal relationship between DHA levels and prognosis is uncertain.

\section{Conclusions}

Lower levels of DHA are significantly associated with an increase in all-cause death in patients with acute decompensated HFpEF, independent of nutritional status. Measurement of plasma DHA levels may be useful in identifying high-risk patients with HFpEF, and supplementation with DHA may be a potential therapeutic target in these patients.

Author Contributions: Conceptualization, A.T.; formal analysis, N.M. and T.M.; data curation, N.M.; T.K., K.Y., M.T., Y.N., N.O., and M.U.; investigation, N.M.; A.T.; T.K., K.Y., M.T., Y.N., N.O., and M.U.; writing—original draft preparation, N.M.; writing—Review and Editing, T.M.; A.T.; T.K., K.Y., M.T., Y.N., N.O., and M.U.; project administration, H.I. All authors have read and agreed to the published version of the manuscript.

Funding: This research received no external funding.

Institutional Review Board Statement: The study protocol was approved by the Institutional Review Board of Mitoyo General Hospital (19CR01-122).

Informed Consent Statement: Patient consent was waived because of the low-risk nature of the study and inability to obtain consent directly from all the study subjects.

Data Availability Statement: The data presented in this study are available on request from the corresponding author.

Conflicts of Interest: The authors declare no conflict of interest.

\section{References}

1. Ziaeian, B.; Fonarow, G.C. Epidemiology and aetiology of heart failure. Nat. Rev. Cardiol. 2016, 13, 368-378. [CrossRef] [PubMed]

2. Virani, S.S.; Alonso, A.; Benjamin, E.J.; Bittencourt, M.S.; Callaway, C.W.; Carson, A.P.; Chamberlain, A.M.; Chang, A.R.; Cheng, S.; Delling, F.N.; et al. Heart Disease and Stroke Statistics-2020 Update: A Report From the American Heart Association. Circulation 2020, 141, e139-e596. [CrossRef] [PubMed]

3. Butler, J.; Fonarow, G.C.; Zile, M.R.; Lam, C.S.; Roessig, L.; Schelbert, E.B.; Shah, S.J.; Ahmed, A.; Bonow, R.O.; Cleland, J.G.; et al. Developing therapies for heart failure with preserved ejection fraction: Current state and future directions. JACC Heart Fail. 2014, 2, 97-112. [CrossRef] [PubMed]

4. Yancy, C.W.; Jessup, M.; Bozkurt, B.; Butler, J.; Casey, D.E., Jr.; Colvin, M.M.; Drazner, M.H.; Filippatos, G.S.; Fonarow, G.C.; Givertz, M.M.; et al. 2017 ACC/AHA/HFSA Focused Update of the 2013 ACCF/AHA Guideline for the Management of Heart Failure: A Report of the American College of Cardiology/American Heart Association Task Force on Clinical Practice Guidelines and the Heart Failure Society of America. Circulation 2017, 136, e137-e161. [CrossRef]

5. Ushigome, R.; Sakata, Y.; Nochioka, K.; Miyata, S.; Miura, M.; Tadaki, S.; Yamauchi, T.; Sato, S.; Onose, T.; Tsuji, K.; et al. Temporal trends in clinical characteristics, management and prognosis of patients with symptomatic heart failure in Japan-Report from the CHART Studies. Circ. J. 2015, 79, 2396-2407. [CrossRef]

6. Narumi, T.; Arimoto, T.; Funayama, A.; Kadowaki, S.; Otaki, Y.; Nishiyama, S.; Takahashi, H.; Shishido, T.; Miyashita, T.; Miyamoto, T.; et al. Prognostic importance of objective nutritional indexes in patients with chronic heart failure. J. Cardiol. 2013, 62, 307-313. [CrossRef]

7. Sokoła-Wysoczańska, E.; Wysoczański, T.; Wagner, J.; Czyż, K.; Bodkowski, R.; Lochyński, S.; Patkowska-Sokoła, B. Polyunsaturated Fatty Acids and Their Potential Therapeutic Role in Cardiovascular System Disorders-A Review. Nutrients 2018, 10, 1561. [CrossRef]

8. Russo, G.L. Dietary n-6 and n-3 polyunsaturated fatty acids: From biochemistry to clinical implications in cardiovascular prevention. Biochem. Pharmacol. 2009, 77, 937-946. [CrossRef]

9. Sakamoto, A.; Saotome, M.; Iguchi, K.; Maekawa, Y. Marine-Derived Omega-3 Polyunsaturated Fatty Acids and Heart Failure: Current Understanding for Basic to Clinical Relevance. Int. J. Mol. 2019, 20, 4025. [CrossRef]

10. Innes, J.K.; Calder, P.C. Omega-6 fatty acids and inflammation. Prostaglandins Leukot. Essent. Fatty Acids 2018, 132, 41-48. [CrossRef]

11. Serhan, C.N. Pro-resolving lipid mediators are leads for resolution physiology. Nature 2014, 510, 92-101. [CrossRef] [PubMed]

12. Frigolet, M.E.; Gutierrez-Aguilar, R. The Role of the Novel Lipokine Palmitoleic Acid in Health and Disease. Adv. Nut. 2017, 8, 173S-181S. [CrossRef] [PubMed]

13. Carrillo, C.; Cavia, M.D.M.; Alonso-Torre, S. Role of oleic acid in immune system; mechanism of action; a review. Nutr. Hosp. 2012, 27, 978-990. [CrossRef] [PubMed] 
14. Sales-Campos, H.; Souza, P.R.; Peghini, B.C.; da Silva, J.S.; Cardoso, C.R. An overview of the modulatory effects of oleic acid in health and disease. Mini Rev. Med. Chem. 2013, 13, 201-210. [CrossRef]

15. Kayama, Y.; Minamino, T.; Toko, H.; Sakamoto, M.; Shimizu, I.; Takahashi, H.; Okada, S.; Tateno, K.; Moriya, J.; Yokoyama, M.; et al. Cardiac 12/15 lipoxygenase-induced inflammation is involved in heart failure. J. Exp. Med. 2009, 206, 1565-1574. [CrossRef]

16. Endo, J.; Sano, M.; Isobe, Y.; Fukuda, K.; Kang, J.X.; Arai, H.; Arita, M. 18-HEPE, an n-3 fatty acid metabolite released by macrophages, prevents pressure overload-induced maladaptive cardiac remodeling. J. Exp. Med. 2014, 211, 1673-1687. [CrossRef]

17. Kunapuli, P.; Lawson, J.A.; Rokach, J.A.; Meinkoth, J.L.; FitzGerald, G.A. Prostaglandin F2alpha (PGF2alpha) and the isoprostane, 8, 12-iso-isoprostane F2alpha-III, induce cardiomyocyte hypertrophy. Differential activation of downstream signaling pathways. J. Biol. Chem. 1998, 273, 22442-22452. [CrossRef]

18. GISSI-Prevenzione Investigators (Gruppo Italiano per lo Studio della Sopravvivenza nell'Infarto miocardico). Dietary supplementation with n-3 polyunsaturated fatty acids and vitamin E after myocardial infarction: Results of the GISSI-Prevenzione trial. Lancet 1999, 354, 447-455. [CrossRef]

19. Mozaffarian, D.; Lemaitre, R.N.; King, I.B.; Song, X.; Spiegelman, D.; Sacks, F.M.; Rimm, E.B.; Siscovick, D.S. Circulating long-chain $\omega$-3 fatty acids and incidence of congestive heart failure in older adults: The cardiovascular health study: A cohort study. Ann. Intern. Med. 2011, 155, 160-170. [CrossRef]

20. Bernasconi, A.A.; Wiest, M.M.; Lavie, C.J.; Milani, R.V.; Laukkanen, J.A. Effect of Omega-3 Dosage on Cardiovascular Outcomes: An Updated Meta-Analysis and Meta-Regression of Interventional Trials. Mayo Clin. Proc. 2020. [CrossRef]

21. Djousse, L.; Akinkuolie, A.O.; Wu, J.H.; Ding, E.L.; Gaziano, J.M. Fish consumption, omega-3 fatty acids and risk of heart failure: A meta-analysis. Clin. Nutr. 2012, 31, 846-853. [CrossRef] [PubMed]

22. Block, R.C.; Liu, L.; Herrington, D.M.; Huang, S.; Tsai, M.Y.; O'Connell, T.D.; Shearer, G.C. Predicting Risk for Incident Heart Failure With Omega-3 Fatty Acids: From MESA. JACC Heart Fail. 2019, 7, 651-661. [CrossRef] [PubMed]

23. Nodari, S.; Triggiani, M.; Campia, U.; Manerba, A.; Milesi, G.; Cesana, B.M.; Gheorghiade, M.; Dei Cas, L. Effects of n-3 polyunsaturated fatty acids on left ventricular function and functional capacity in patients with dilated cardiomyopathy. J. Am. Coll. Cardiol. 2011, 57, 870-879. [CrossRef]

24. Chrysohoou, C.; Metallinos, G.; Georgiopoulos, G.; Mendrinos, D.; Papanikolaou, A.; Magkas, N.; Pitsavos, C.; Vyssoulis, G.; Stefanadis, C.; Tousoulis, D. Short term omega-3 polyunsaturated fatty acid supplementation induces favorable changes in right ventricle function and diastolic filling pressure in patients with chronic heart failure; A randomized clinical trial. Vasc. Pharmacol. 2016, 79, 43-50. [CrossRef] [PubMed]

25. Kohashi, K.; Nakagomi, A.; Saiki, Y.; Morisawa, T.; Kosugi, M.; Kusama, Y.; Atarashi, H.; Shimizu, W. Effects of eicosapentaenoic acid on the levels of inflammatory markers, cardiac function and long-term prognosis in chronic heart failure patients with dyslipidemia. J. Atheroscler. Thromb. 2014, 21, 712-729. [CrossRef]

26. Moertl, D.; Hammer, A.; Steiner, S.; Hutuleac, R.; Vonbank, K.; Berger, R. Dose-dependent effects of omega-3-polyunsaturated fatty acids on systolic left ventricular function, endothelial function, and markers of inflammation in chronic heart failure of nonischemic origin: A double-blind, placebo-controlled, 3-arm study. Am. Heart. J. 2011, 161, 915.e1-915.e9. [CrossRef]

27. O'Keefe, E.L.; Harris, W.S.; DiNicolantonio, J.J.; Elagizi, A.; Milani, R.V.; Lavie, C.J.; O'Keefe, J.H. Sea Change for Marine Omega-3s: Randomized Trials Show Fish Oil Reduces Cardiovascular Events. Mayo Clin. Proc. 2019, 94, 2524-2533. [CrossRef]

28. Elagizi, A.; Lavie, C.J.; O’Keefe, E.; Marshall, K.; O’Keefe, J.H.; Milani, R.V. An Update on Omega-3 Polyunsaturated Fatty Acids and Cardiovascular Health. Nutrients 2021, 13, 204. [CrossRef]

29. McKee, P.A.; Castelli, W.P.; McNamara, P.M.; Kannel, W.B. The natural history of congestive heart failure: The Framingham study. N. Engl. J. Med. 1971, 285, 1441-1446. [CrossRef]

30. Yanagisawa, N.; Shimada, K.; Miyazaki, T.; Kume, A.; Kitamura, Y.; Ichikawa, R.; Ohmura, H.; Kiyanagi, T.; Hiki, M.; Fukao, K.; et al. Polyunsaturated fatty acid levels of serum and red blood cells in apparently healthy Japanese subjects living in an urban area. J. Atheroscler. Thromb. 2010, 17, 285-294. [CrossRef]

31. Matsuo, S.; Imai, E.; Horio, M.; Yasuda, Y.; Tomita, K.; Nitta, K.; Yamagata, K.; Tomino, Y.; Yokoyama, H.; Hishida, A.; et al. Revised equations for estimated GFR from serum creatinine in Japan. Am. J. Kidney Dis. 2009, 53, 982-992. [CrossRef] [PubMed]

32. Bouillanne, O.; Morineau, G.; Dupont, C.; Coulombel, I.; Vincent, J.P.; Nicolis, I.; Benazeth, S.; Cynober, L.; Aussel, C. Geriatric Nutritional Risk Index: A new index for evaluating at-risk elderly medical patients. Am. J. Clin. Nutr. 2005, 82, 777-783. [CrossRef] [PubMed]

33. Ouchi, S.; Miyazaki, T.; Shimada, K.; Sugita, Y.; Shimizu, M.; Murata, A.; Kato, T.; Aikawa, T.; Suda, S.; Shiozawa, T.; et al. Low Docosahexaenoic Acid, Dihomo-Gamma-Linolenic Acid, and Arachidonic Acid Levels Associated with Long-Term Mortality in Patients with Acute Decompensated Heart Failure in Different Nutritional Statuses. Nutrients 2017, 9, 956. [CrossRef] [PubMed]

34. Nagai, T.; Honda, Y.; Sugano, Y.; Nishimura, K.; Nakai, M.; Honda, S.; Iwakami, N.; Okada, A.; Asaumi, Y.; Aiba, T.; et al. Circulating Omega-6, But Not Omega-3 Polyunsaturated Fatty Acids, Are Associated with Clinical Outcomes in Patients with Acute Decompensated Heart Failure. PLoS ONE 2016, 11, e0165841. [CrossRef]

35. Ouchi, S.; Miyazaki, T.; Shimada, K.; Sugita, Y.; Shimizu, M.; Murata, A.; Kato, T.; Aikawa, T.; Suda, S.; Shiozawa, T.; et al. Decreased circulating dihomo-gamma-linolenic acid levels are associated with total mortality in patients with acute cardiovascular disease and acute decompensated heart failure. Lipids Health Dis. 2017, 16, 150. [CrossRef]

36. Nieman, D.C.; Mitmesser, S.H. Potential Impact of Nutrition on Immune System Recovery from Heavy Exertion: A Metabolomics Perspective. Nutrients 2017, 9, 513. [CrossRef] 
37. Saito, M.; Ueno, M.; Kubo, K.; Yamaguchi, M. Dose-Response Effect of Dietary Docosahexaenoic Acid on Fatty Acid Profiles of Serum and Tissue Lipids in Rats. J. Agric. Food Chem. 1998, 46, 184-193. [CrossRef]

38. Hamaguchi, S.; Kinugawa, S.; Sobirin, M.A.; Goto, D.; Tsuchihashi-Makaya, M.; Yamada, S.; Yokoshiki, H.; Tsutsui, H.; JCARECARD Investigators. Mode of death in patients with heart failure and reduced vs. preserved ejection fraction: Report from the registry of hospitalized heart failure patients. Circ. J. 2012, 76, 1662-1669. [CrossRef]

39. Fukuhara, M.; Kitazono, T.; Kiyohara, Y. Association between ratio of serum eicosapentaenoic acid to arachidonic acid and risk of cardiovascular disease: The Hisayama Study. Atherosclerosis 2013, 231, 261-267.

40. Domei, T.; Yokoi, H.; Kuramitsu, S.; Soga, Y.; Arita, T.; Ando, K.; Shirai, S.; Kondo, K.; Sakai, K.; Goya, M.; et al. Ratio of serum n-3 to n-6 polyunsaturated fatty acids and the incidence of major adverse cardiac events in patients undergoing percutaneous coronary intervention. Circ. J. 2012, 76, 423-429. [CrossRef]

41. Ueeda, M.; Doumei, T.; Takaya, Y.; Ohnishi, N.; Takaishi, A.; Hirohata, S.; Miyoshi, T.; Shinohata, R.; Usui, S.; Kusachi, S. Association of serum levels of arachidonic acid and eicosapentaenoic acid with prevalence of major adverse cardiac events after acute myocardial infarction. Heart Vessel. 2011, 26, 145-152. [CrossRef] [PubMed]

42. Tavazzi, L.; Maggioni, A.P.; Marchioli, R.; Barlera, S.; Franzosi, M.G.; Latini, R.; Lucci, D.; Nicolosi, G.L.; Porcu, M.; Tognoni, G.; et al. Effect of n-3 polyunsaturated fatty acids in patients with chronic heart failure (the GISSI-HF trial): A randomised, double-blind, placebo-controlled trial. Lancet 2008, 372, 1223-1230. [PubMed]

43. Madingou, N.; Gilbert, K.; Tomaro, L.; Prud'homme Touchette, C.; Trudeau, F.; Fortin, S.; Rousseau, G. Comparison of the effects of EPA and DHA alone or in combination in a murine model of myocardial infarction. Prostaglandins Leukot. Essent. Fat. Acids 2016, 111, 11-16. [CrossRef] [PubMed]

44. Chen, J.; Shearer, G.C.; Chen, Q.; Healy, C.L.; Beyer, A.J.; Nareddy, V.B.; Gerdes, A.M.; Harris, W.S.; O'Connell, T.D.; Wang, D. Omega-3 fatty acids prevent pressure overload-induced cardiac fibrosis through activation of cyclic GMP/protein kinase G signaling in cardiac fibroblasts. Circulation 2011, 123, 584-593. [CrossRef] [PubMed] 